\title{
Élites, alternancia y partidos políticos en el Estado de México: entre la pluralidad, la búsqueda del voto y el debilitamiento institucional
}

\author{
JaVier ArZuaga-Magnoni \\ ORLANDO ESPINOSA-SANTIAGO \\ José JaVIER Niño-MartíneZ*
}

\begin{abstract}
This paper analyses the difficulties encountered by the parties' elite in the increase of competition in the Governor's election in the State of Mexico. Starting from the elite centrality in competitive democracy, this paper revises the favourable relationship between socio-economical development and alternation. It shows how in spite of the existence of an encouraging panorama for the success of the opposition against PRI (Partido Revolucionario Institucional - Institutional Revolutionary Party) alternation is not achieved. Furthermore, the paper examines the distancing process observed in the different political parties facing increasing political complexity and their difficulties for cohesion during electoral disputes. Finally, we present the behaviour of the local parties' elite in the 2005 election and their impact on the results
\end{abstract}

Keywords: parties' elite, competitive democracy, elections.

\section{Resumen}

Este trabajo analiza las dificultades que enfrentaron las élites partidarias ante el incremento de la competencia de cara a la elección por la gubernatura mexiquense. Partiendo de la centralidad de las élites en la democracia competitiva, se revisa la relación favorable entre desarrollo socioeconómico y alternancia; y se muestra cómo la alternancia no se alcanza, a pesar de que exista un panorama alentador para el arribo de la oposición al PRI. Se examina el proceso de distanciamiento observado en los partidos políticos ante el incremento de la complejidad política y sus dificultades para cohesionarse durante las disputas electorales. Por último, se presentan los comportamientos de las élites partidarias locales en la elección de 2005 y los efectos de éstos en los resultados.

Palabras clave: élites partidarias, democracia competitiva, elecciones.

*Universidad Autónoma del Estado de México. Correos-e: arzuaga.javier@gmail.com, maffesoli@hotmail.com,xhamaco@hotmail.com 


\section{Introducción}

México está viviendo transformaciones derivadas de su arribo a la tan prometida democracia. Si bien es cierto que su transición fue larga y sui generis, ahora enfrenta el dilema de una consolidación donde se pone a prueba la eficacia de las instituciones y de las reglas.

En el presente trabajo se abordan los dilemas que enfrentaron los partidos políticos, en tanto que instituciones, y sus dirigencias para sobrevivir y consolidarse como actores centrales de la competencia política en ambientes regionales, particularmente en el Estado de México.

La singular institucionalización de los partidos en la transición mexicana los expone a riesgos muy fuertes de división y colapso, al tiempo que, gracias a la competencia política, se refuerza el papel de las élites partidarias para que, en su búsqueda de ascenso y poder, se fortalezcan como actores estratégicos. En este contexto, la competencia política electoral se ve determinada por un momento previo que tiene que ver con los procesos internos que llevan a los partidos a proponer candidatos y la eficacia con que evitan que los mismos socaven sus propias bases para la unidad.

El argumento central es que las élites partidarias locales pueden garantizar la unidad y disciplina de los políticos en los momentos de elegir candidatos, en función de su capacidad para distribuir recursos atractivos entre ellos, con la promesa de prolongar sus carreras con relativo éxito. En el caso que estamos analizando, ofrecer expectativas de crecimiento en la política nacional puede garantizar la unidad y disciplina, a pesar de las manifestaciones y riesgos de ruptura. A su vez, la unidad y disciplina de la élite partidaria puede ser un recurso decisivo para el triunfo electoral, en ausencia de la función unificadora de las dirigencias y de las ideologías, y en tiempos en que la competencia electoral debilita sus mecanismos tradicionales de cohesión.

Como señala Przeworski (1995), la posibilidad de que un grupo en particular imponga sus resultados y neutralice a los demás utilizando a las instituciones, provocaría su caída. Sin embargo, como lo muestra la coyuntura electoral del 2005 en el Estado de México, en ese ambiente competitivo donde se utiliza la institución política a favor de un grupo dominante en particular, es la posibilidad de que todos salgan ganando mediante algún recurso extraordinario lo que permite mantener sólidamente unidas las estructuras de los partidos. La institución a la que no se le pre- 
senta ese factor de unidad y expectativa se debilita en un ambiente de competencia. Aquí radica la paradoja de los partidos y sus élites en un ambiente competitivo y democrático.

La democracia contemporánea no ha eliminado el margen de acción de las élites partidarias locales, más bien las ha hecho funcionales en la medida en que reclaman para sí un espacio de dominio y un control sobre las instituciones políticas y, específicamente, sobre los partidos políticos.

\section{Democracia competitiva: reglas, instituciones y recursos}

La democracia en las sociedades contemporáneas es un régimen político donde ningún actor tiene la certeza acerca de los resultados en una contienda electoral. Particularmente hay una vertiente teórica que enfatiza el valor de la competencia de las fuerzas políticas como el acto más significativo de la fortaleza democrática de un país. En la versión clásica de la democracia competitiva, el pueblo sólo se limita a crear un gobierno del conjunto de élites políticas, a través de elecciones que garanticen la competencia por el voto popular y la alternancia de aquéllas en el poder (Schumpeter, 1983).

Para la vertiente competitiva lo interesante es que las élites políticas luchen por ganarse el apoyo del electorado y por ello presenten diversas propuestas dirigidas a un conjunto de problemáticas y asuntos que la ciudadanía y los medios de comunicación tienen como prioritarios. La finalidad es que el electorado sancione y legitime la propuesta de gobierno y a los candidatos que determinado partido político proponga. Lo importante es que se garantice la imparcialidad de las instituciones encargadas de organizarlo, que no se excluyan las incipientes organizaciones políticas que quieran participar y promover sus intereses, que nadie tenga la posibilidad de imponer su llana voluntad al conjunto de la sociedad y que se observen las reglas que establecen los requisitos y las conductas esperadas.

En este contexto, los actores políticos tratan de maximizar sus ventajas y optimizar sus recursos. Entran en un escenario donde ponen en marcha diversas estrategias para ganar y obtener el mayor apoyo del amplio espectro del electorado, pero a su vez para fortalecer a sus propias instituciones partidistas en aras de lograr la adaptación a la competencia.

Así, señala Przeworski (1995), los resultados en una democracia dependerán de las instituciones que regulan la competen- 
cia y los recursos específicos con los que cuenten los actores, y obviamente de las estrategias prácticas que pongan en marcha en los procesos políticos. En este sentido, las élites políticas y su competencia facilitarían la pluralidad y por ende la alternancia en un contexto de reformas político-electorales, modernización económica y avance político opositor en el ámbito nacional. Ahí se pondría a prueba la capacidad de los actores por identificar las demandas del electorado.

\section{La alternancia que no llega}

México transitó a la democracia de una manera poco ortodoxa, si es que tal cosa existe, lo cual se manifestó en la diversidad de interpretaciones que de ella se hicieron. Menos diferencias generó la idea de que las reformas y la competencia electorales tuvieron un papel central en el proceso. En cambio, donde parece no haber discrepancia entre los múltiples estudios sobre este fenómeno político, es en el proceso de transformación de largo plazo donde se inscriben los cambios institucionales que caracterizaron a la transición mexicana. En efecto, hasta donde hemos podido documentar, es unánime la opinión de que un cambio en la estructura socioeconómica y demográfica de la sociedad mexicana explica, en última instancia, el camino hacia la democratización del régimen político mexicano posrevolucionario. ${ }^{1}$

Esta estrategia de explicación, seguida por los estudiosos de la transición mexicana, fue igualmente utilizada por la mayoría de quienes hicieron investigaciones más específicamente electorales. Estos estudios han intentado dar cuenta no sólo a escala nacional, sino en el ámbito de las entidades federativas, que era ésta una realidad que se repetía sistemáticamente. ${ }^{2}$

Si seguimos la lógica de estas argumentaciones en el terreno electoral, deberíamos percibir un incremento en la competitividad electoral, primero, y de la alternancia política, después, en buena parte del territorio nacional, iniciando con aquellos estados más modernos y desarrollados, entre los que el Estado de México debería estar. La pluralización del electorado y la desintegración de la coalición social que fundamentó la hegemonía priísta, en el marco de instituciones que amplían las posibilida-

${ }^{1}$ Como casos paradigmáticos de estas interpretaciones pueden verse los trabajos de Becerra, Salazar y Woldenberg (2000), Cansino (2000) o Molinar Horcasitas (1991).

${ }^{2}$ En este caso pueden resultar ilustrativos los trabajos de Peschard (1988) y Pacheco (2000). 
des de la competencia electoral, deberían generar en el mediano plazo alternancia en el poder.

Con el objeto de analizar la particularidad del caso mexiquense, en el cuadro 1 se muestran las entidades federativas del país distribuidas de acuerdo con dos variables: la primera, en el eje vertical divide al conjunto de entidades según su ubicación por debajo o por encima de la mediana en cuanto a modernización y desarrollo, medidos a partir del índice de marginación del Consejo Nacional de Población (Conapo); la segunda, en el eje horizontal, divide en dos dicho conjunto de acuerdo con que haya presentado, o no, alternancia en la gubernatura.

\section{Cuadro 1}

Alternancia en la gubernatura de los estados según grado de marginación hasta 2006

\begin{tabular}{lll}
\hline & Conalternancia & Sin alternancia \\
\hline Estados con grado de & Chiapas & Campeche \\
marginación por & Guanajuato & Hidalgo \\
encima de la mediana & Guerrero & Oaxaca \\
& Michoacán & Puebla \\
& Nayarit & Sinaloa \\
& Querétaro & Tabasco \\
& San Luis Potosí & Veracruz \\
& Yucatán & \\
Estados con grado de & Zacatecas & Coahuila \\
marginación por debajo & Aguascalientes & Durango \\
de la mediana & Baja California & Estado de México \\
& Baja California Sur & Quintana Roo \\
& Chihuahua & Sonora \\
& Colima & Tamaulipas \\
& Distrito Federal & \\
& Jalisco & \\
& Morelos & \\
& Nuevo León & \\
& Tlaxcala & \\
\hline
\end{tabular}

Fuente: Elaboración propia con datos del Conapo (1995), Banamex (2005), Cidac (2006).

Dispuestos los datos de esta manera, nos encontramos con que, si bien la relación no es demasiado fuerte, alrededor de 53\% de las entidades federativas que presentan alternancia en la gubernatura se encuentran por debajo de la mediana del índice de marginación; mientras que alrededor de $54 \%$ de las que no presentan alternancia se encuentra por encima de la mediana de dicho índice. Entre los estados más desarrollados y modernos, $62.5 \%$ muestra alternancia, mientras que $37.5 \%$ no. En este últi- 
mo grupo se encuentra el Estado de México, cuando, de acuerdo con las previsiones de la teoría, debería presentar alternancia en el ámbito de la gubernatura.

Algunos elementos adicionales hacen particularmente atípica la falta de alternancia en la gubernatura mexiquense. De las tres elecciones presidenciales celebradas entre 1988 y 2000, los electores mexiquenses prefirieron a un partido distinto del PRI en dos ocasiones (1988 y 2000). Los datos preliminares de las elecciones presidenciales del pasado 2 de julio incrementarían este número a tres de cuatro. Lo cual, en cambio, respalda la teoría.

Si tomamos los resultados electorales por entidad federativa de las elecciones de diputados federales entre 1991 y 2003, el Estado de México se encuentra siempre entre las entidades en las que el PRI obtiene menor porcentaje de votos. En 1991 la entidad estuvo siete puntos porcentuales por debajo del total nacional y se ubicó como la tercera donde el PRI consiguió menor porcentaje de votos; entre 1994 y 2000 se mantuvo siempre cuatro puntos porcentuales por debajo del total nacional, quedando en cuarto sitio en 1994, en tercero en 1997 y en sexto en el 2000; en 2003 se ubicó en noveno sitio, dos puntos porcentuales por debajo del total nacional (Banamex, 2005). Nuevamente aquí los datos respaldan la teoría.

Los cuadros 2 y 3 nos permiten visualizar la situación de las legislaturas locales. En el cuadro 2 se distribuyen las entidades federativas a partir de dos variables: en el eje vertical mantenemos la división de acuerdo con la mediana del índice de marginación, y en el eje horizontal se dividen dichas entidades en virtud de haber tenido o no legislaturas sin mayoría absoluta priísta.

Si bien la mayor parte de las entidades federativas tuvieron al menos una legislatura sin mayoría absoluta priísta (75\%), la proporción es mayor entre las más modernas y desarrolladas. ${ }^{3}$ Por su parte, si tomamos en cuenta sólo la columna que contiene los estados con al menos una legislatura sin mayoría absoluta priísta, $54.2 \%$ se encuentra entre las más modernas y desarrolladas. En este caso, el Estado de México tampoco es excepción.

El cuadro 3 reúne sólo las entidades federativas que tuvieron al menos una legislatura sin mayoría absoluta priísta y se dividen de acuerdo con dos variables: en el eje vertical continuamos con la división de acuerdo con la mediana del índice de marginación,

${ }^{3}$ El $81.3 \%$ de los estados con grados de marginación por debajo de la mediana han tenido al menos una legislatura sin mayoría priísta. Dicho porcentaje se reduce a $70.6 \%$ en el caso de los estados con grados de marginación por encima de la mediana. 


\section{Cuadro 2}

Estados según grado de marginación y existencia de legislaturas sin mayoría priísta hasta 2006

\begin{tabular}{|c|c|c|}
\hline & $\begin{array}{l}\text { Con legislaturas } \\
\text { sin mayoría priísta }\end{array}$ & $\begin{array}{c}\text { Con legislaturas } \\
\text { sólo de mayoría priísta }\end{array}$ \\
\hline $\begin{array}{l}\text { Estados con grado de } \\
\text { marginación por encima } \\
\text { de la mediana }\end{array}$ & $\begin{array}{l}\text { Chiapas } \\
\text { Guanajuato } \\
\text { Guerrero } \\
\text { Michoacán } \\
\text { Nayarit } \\
\text { Querétaro } \\
\text { Quintana Roo } \\
\text { San Luis Potosí } \\
\text { Tabasco } \\
\text { Veracruz } \\
\text { Yucatán } \\
\text { Zacatecas }\end{array}$ & $\begin{array}{l}\text { Campeche } \\
\text { Hidalgo } \\
\text { Oaxaca } \\
\text { Puebla } \\
\text { Sinaloa }\end{array}$ \\
\hline $\begin{array}{l}\text { Estados con grado de } \\
\text { marginación por debajo } \\
\text { de la mediana }\end{array}$ & $\begin{array}{l}\text { Aguascalientes } \\
\text { Baja California } \\
\text { Baja California Sur } \\
\text { Chihuahua } \\
\text { Colima } \\
\text { Distrito Federal } \\
\text { Estado de México } \\
\text { Jalisco } \\
\text { Morelos } \\
\text { Nuevo León } \\
\text { Sonora } \\
\text { Tlaxcala }\end{array}$ & $\begin{array}{l}\text { Coahuila } \\
\text { Durango } \\
\text { Tamaulipas }\end{array}$ \\
\hline
\end{tabular}

Fuente: Elaboración propia con datos del Conapo (1995), Banamex (2005), CIDAC (2006).

y en el horizontal, se dividen de acuerdo con que su primera legislatura sin mayoría absoluta priísta se haya presentado antes o después de $1997 .{ }^{4}$

En este caso, el cuadro nos permite observar que todas las entidades federativas menos modernas y desarrolladas tuvieron su primera legislatura sin mayoría priísta en 1997 o en años posteriores; las más modernas y desarrolladas, en cambio, se dividen por mitades. El Estado de México se encuentra entre las primeras seis en tener una legislatura sin mayoría priísta, en este caso tampoco es excepción.

Los datos precedentes sirven para mostrar que en el único ámbito en que el PRI no ha sido derrotado en la entidad es en la gubernatu-

${ }^{4}$ Tomamos esta fecha dado que en ese año la Cámara de Diputados federal tuvo esas características. 


\section{Cuadro 3}

Estados según grado de marginación y año de instalación de legislaturas sin mayoría priísta

\begin{tabular}{|c|c|c|}
\hline & $\begin{array}{l}\text { Con legislaturas } \\
\text { sin mayoría priísta } \\
\text { antes de } 1997\end{array}$ & $\begin{array}{l}\text { Con legislaturas } \\
\text { sin mayoría priísta } \\
\text { a partir de } 1997\end{array}$ \\
\hline $\begin{array}{l}\text { Estados con grado de } \\
\text { marginación por encima } \\
\text { de la mediana }\end{array}$ & & $\begin{array}{l}\text { Chiapas } \\
\text { Guanajuato } \\
\text { Guerrero } \\
\text { Michoacán } \\
\text { Nayarit } \\
\text { Querétaro } \\
\text { Quintana Roo } \\
\text { San Luis Potosí } \\
\text { Tabasco } \\
\text { Veracruz } \\
\text { Yucatán } \\
\text { Zacatecas }\end{array}$ \\
\hline $\begin{array}{l}\text { Estados con grado de } \\
\text { marginación por debajo } \\
\text { de la mediana }\end{array}$ & $\begin{array}{l}\text { Aguascalientes } \\
\text { Baja California } \\
\text { Baja California Sur } \\
\text { Chihuahua } \\
\text { Estado de México } \\
\text { Jalisco }\end{array}$ & $\begin{array}{l}\text { Colima } \\
\text { Distrito Federal } \\
\text { Morelos } \\
\text { Nuevo León } \\
\text { Sonora } \\
\text { Tlaxcala }\end{array}$ \\
\hline
\end{tabular}

Fuente: Elaboración propia con datos del Conapo (1995), Banamex (2005), CIDAC (2006).

ra y el carácter excepcional de este hecho. El resto de las elecciones reflejan una pluralidad que no se ha transformado en alternancia en el gobierno estatal, incluso las elecciones para gobernador presentan a favor del PRI los márgenes de victoria más abultados. De hecho, de acuerdo con las tendencias electorales de los últimos años, la elección propicia para el triunfo de la oposición en la gubernatura era la del 2005, y en ese caso el PRI mostró como nunca a lo largo de la última década un triunfo por más de 20 puntos porcentuales. La pregunta es: ¿qué lo hizo propicio?

\section{La cartelización de los partidos mexicanos}

Resulta un hecho evidente que el PRI no ha perdido nunca la gubernatura del Estado de México. El apartado anterior buscó documentar que se trata de un hecho excepcional en el ámbito nacional y que la entidad cuenta con las bases sociales para la alternancia. La ausencia de ésta debe explicarse más por la dinámica del sistema político mexiquense que por las condiciones sociales que la hacen posible. 
En este sentido, es pertinente abandonar hasta cierto punto el ambiente y dirigirnos hacia la organización, composición y reglas al interior de los partidos. En este caso, las condiciones sociales presionan hacia la dispersión y pluralidad políticas, pero no bastan para que se vean reflejadas automáticamente en la alternancia en el gobierno. Los partidos deben tener la capacidad para unificar a sus grupos y con ello reducir la complejidad del ambiente, con el propósito de ganar el poder y poner en marcha sus proyectos.

La ruta de la cartelización ${ }^{5}$ de los partidos políticos, no obstante permitir su profesionalización electoral, no les proporciona cohesión y convicción de unificarse para enfrentar con eficacia la contienda política.

El hecho que se quiere destacar es que en los partidos cárteles, el aparato pierde importancia, los dirigentes se transforman en políticos profesionales o especialistas que buscan puestos en el gobierno; estos líderes, en la medida en que ganan votos, se vuelven autónomos de las estructuras partidarias e influyen en ellas desde afuera mucho más que los representantes de la estructura. La estructura partidaria debilitada se vuelve incapaz de asegurar la lealtad de sus miembros y, más allá de los políticos profesionales, el partido sólo apela a los electores, se dedica a intensas campañas electorales y enfatiza su especialización y eficiencia para gobernar; función principal es la de asegurar su acceso o permanencia en el gobierno (Reveles, 2005).

En México la cartelización de los partidos políticos fue producto de las reformas electorales. A partir de ellas, los partidos se hicieron de amplios recursos públicos y la mayor equidad en la competencia los llevó a aspirar a los incentivos materiales que otorga el acceso al poder. Si antes la clase política priísta tenía una gran capacidad para amalgamarse con disidencias de signo

\footnotetext{
${ }^{5}$ Entendemos por cartelización de los partidos políticos un proceso de transformación que va de su estructuración como partidos de masas, en el sentido descrito por Duverger (1981), a partidos cártel o en public office, pasando por una forma de organización como atrapa todo, estos dos últimos tipos de acuerdo con las descripciones de Katz y Mair (citados por Reveles, 2005).

En particular queremos hacer referencia a un conjunto de cambios en la estructura de los partidos que podrían sintetizarse de la siguiente manera: a) abandono del financionamiento de la estructura partidaria y de las campañas electorales por parte de la base militante y su reemplazo por la recaudación con base en gestores, primero, y el financiamiento público, después; b) la sustitución de una amplia y compleja trama organizacional por una dirigencia reducida y profesionalizada, primero, y por los gobernantes y parlamentarios provenientes del partido, después; c) el reemplazo de los discursos dirigidos a públicos ideológicamente identificados con el partido a discursos dirigidos a públicos más amplios (Reveles, 2005).
} 
ideológico diverso, pero proclives a la negociación, ahora los privilegios de los cuales disfrutaba el PRI fueron también compartidos por sus adversarios, especialmente, los partidos Acción Nacional (PAN) y el de la Revolución Democrática (PRD). El elevado monto de las remuneraciones para los funcionarios públicos y su manejo discrecional contribuyeron a fortalecer a los partidos políticos en tanto vehículos para acceder al poder. Pero debilitó sus vínculos con la sociedad y a los líderes partidistas, transformándose así en partidos cárteles (Reveles, 2005).

\section{Las élites partidarias en la competencia electoral}

La cartelización de los partidos políticos mexicanos nos acerca al centro de nuestra argumentación. Lejos de contar con sólidas estructuras políticas con amplias bases de militantes, las élites de los partidos cártel han apostado todo a la movilización de recursos para ganar elecciones. El triunfo electoral, por su parte, se ha convertido en la única condición de supervivencia de los partidos y el ocupar cargos públicos en la única razón de ser de los políticos profesionales. A su vez, la electoralización de los comportamientos partidarios genera una actuación instrumental de los votantes que refuerza la importancia de lo electoral como único referente de la acción de los políticos (Peschard, 2005).

En este contexto, la dinámica de las élites partidarias empieza a ser vital para su supervivencia. Todavía hace pocos años, para formar parte de la llamada clase política, y en consecuencia para tener una carrera política exitosa, había que sumarse a las filas del PRI, no hacerlo significaba cerrar las posibilidades de triunfo tanto a corto como a largo plazo. Sin embargo, actualmente al haber una dinámica de competencia electoral (en la que militar y contender por otro partido también representa posibilidades reales de obtener triunfos en las urnas), la ecuación se ha vuelto más compleja, ya no basta ser postulado por el PRI para tener un triunfo automático; más aún, el hecho de tener asegurado el triunfo de la elección permitía que los interesados en ocupar algún cargo público pudieran circular fácilmente en los puestos (presidencias municipales, diputaciones federales y locales), pero ahora la incertidumbre en los resultados se ha extendido a la incertidumbre para elegir candidatos debido a que la rotación en los cargos de elección se ha ampliado a otros institutos políticos que también pueden ganar elecciones. La dirigencia de los principales partidos políticos tendrá éxito en tanto pueda atenuar las luchas de intereses y cohesionar a los competidores alrededor de 
reglas claras, pero hay que reconocer que actualmente las demandas de representación y la cada vez más cuestionada disciplina partidista dificultan la posibilidad de tomar acuerdos en torno de dichas reglas.

En virtud de la competencia política, las carreras personales de los políticos entran en oposición con la unidad partidaria, orillándolos a la dinámica descrita por Olson en relación con las organizaciones: "si los miembros de un grupo grande tratan racionalmente de maximizar su bienestar personal, no actuarán para favorecer sus objetivos comunes o de grupo a menos que haya coacción para obligarlos a hacerlo o a menos que se les ofrezca individualmente algún incentivo por separado, distinto de la satisfacción del interés común o de grupo, con la condición de que ayuden a soportar los costos o las cargas que implica el logro de los objetivos del grupo" (Olson, 1992: 12). Desde nuestro punto de vista, las élites partidarias se mantienen unidas en una competencia electoral si las posibilidades de tener carreras políticas más exitosas, que las que tendrían si hubiesen actuado de manera no cooperativa, se ofrecen a sus integrantes a cambio de la disciplina; de lo contrario éstos actuarán de manera tal que en la búsqueda de su beneficio propio provocarán la desintegración de la unidad partidaria produciendo una catástrofe colectiva desde el punto de vista de los intereses del partido como organización.

La revisión de las actuaciones de las élites de los tres principales partidos políticos parece corroborar las dificultades que enfrentan para lograr la unidad, a pesar de las condiciones favorables en el terreno electoral y de sus expectativas en las dirigencias nacionales.

\section{La mítica unidad del PRI mexiquense}

Si hay algo que se dice de los políticos priístas del Estado de México es que han sabido mantenerse unidos frente a los distintos sucesos que han amenazado su supervivencia a lo largo de la historia. Esto ha dado lugar, de acuerdo con Hernández (1998, 1999), al mito del dominio, homogeneidad y control político del Grupo Atlacomulco. Este mito, ampliamente sostenido por los medios de comunicación y por buena parte de la opinión pública, fue potenciado desde un conjunto de estudios que buscaban dar cuenta de la autonomía y unidad de una clase política que conseguía extender su supremacía en escenarios de profundos cambios. En términos generales, las clases políticas locales en México (incluida la mexiquense antes del desembarco de Isidro Fabela) habían conse- 
guido la estabilidad a cambio de la pérdida de autonomía, o ésta a cambio de la inestabilidad y el caudillismo. Estabilidad, institucionalización y autonomía, características todas de la clase política mexiquense, eran su distinción y su enigma.

Salazar (1993) sostiene que la unidad se originó ante la necesidad de encontrar canales institucionales para dirimir los conflictos y lograr el irrestricto apoyo a los proyectos del gobernador en turno, incluidos por supuesto, los electorales. Para lograrlo, "en el Estado de México los grupos y liderazgos tienden a mezclarse. Es posible, por lo tanto, encontrar a miembros prominentes, y aun dirigentes de un determinado grupo, como integrantes de otro distinto" (Salazar, 1993: 36).

Es decir, la definición de ciertas reglas políticas propició la formación de una red, y no un grupo, lo que permitió la flexibilidad y durabilidad de la clase política ante las distintas coyunturas o periodos de gobierno. Salazar (1993) resalta el importante papel del establecimiento de las reglas para lograr la unidad y con ello, mantenerse en el poder:

\footnotetext{
...la clase política del Estado de México se ha distinguido por su cohesión interna y por la ausencia -generalmente- de contradicciones irreconciliables entre los distintos equipos. Es así que el arribo al poder de uno de ellos, no suele significar el radical desalojo del grupo precedente o de los demás en el nuevo gabinete. Normalmente el gobernador en turno invita a colaborar en su administración a conspicuos miembros de otros grupos, como una fórmula eficaz de equilibrio entre ellos (Salazar, 1993:36).
}

Hernández (1998 y 1999) coincide en que existe una basta red de grupos políticos que efectivamente han sabido conservar lealtades, no siempre con la misma eficacia ni con iguales fórmulas. En la medida en que no se trata de un solo grupo capaz de mantener a sus miembros en la gubernatura estatal, es posible comprender la valía y la complejidad de la unidad que han sostenido por décadas.

A su vez, la dinámica de expansión de la red de políticos priístas mexiquenses estuvo ligada a la estrategia seguida por los gobernadores, consistente en el reclutamiento de jóvenes políticos que con el tiempo formaron sus propias redes y grupos, fincados más en una visión de liderazgo estatal que en un control férreo sobre las carreras de nuevas generaciones (Hernández, 1999).

Particularmente desde mediados del siglo xx, la relación constante de tensión entre la élite local y la nacional, ubicada ésta en el Distrito Federal, hizo que la unidad y la disciplina fueran fac- 
tores importantes para el éxito y la estabilidad de la primera. Sobre todo porque sólo así se evitarían de nuevo imposiciones del centro al margen de los políticos mexiquenses.

Los años ochenta fueron escenario de sucesos hasta entonces poco comunes para el país e insospechados para el Estado de México. Por un lado, la eficacia de los políticos mexiquenses los había puesto, nuevamente, en la antesala del poder ejecutivo federal. Continuos traslados de los máximos referentes locales hacia las oficinas del Distrito Federal provocaron, paradójicamente, un debilitamiento de la gubernatura. Los permanentes cambios en Toluca y las dificultades para producir sustitutos igualmente eficaces, aunados a los golpes recibidos por las disputas en el ámbito federal terminaron por producir un acontecimiento que desde la aparición de Isidro Fabela en el escenario político estatal no acontecía: la irrupción de un político con poco arraigo local en la gubernatura mexiquense. A la llegada de Mario Ramón Beteta los mexiquenses imputaron la debacle electoral del PRI en 1988 en la entidad. La posterior recomposición de dicho partido y la recuperación electoral de 1991 y 1993 parecieron ratificar el diagnóstico.

Según Hernández, Mario Ramón Beteta es muestra de la "mayor dispersión política y falta de liderazgo que se tradujo en un desastre local y nacional al coincidir con los disputados comicios de 1988" (1999: 469). Al finalizar este desastroso periodo, Pichardo Pagaza fue llamado por el presidente Salinas de Gortari para reunificar a la élite y encauzar de mejor manera los destinos electorales de la entidad, respetando la representatividad de los grupos, pero sin poder evitar la creciente heterogeneidad política y sin haber construido un grupo apropiado para tales circunstancias.

Según el mismo autor, Emilio Chuayffet fue quien violentó las normas de comportamiento y observancia de la élite, pues marginó a miembros de la clase política tradicional y sólo incluyó en su gabinete a quienes le mostraban lealtad probada y fácil control. Con este hecho, los riesgos de fractura de la élite cada vez fueron más palpables.

A pesar de las advertencias de Hernández (1999), lo cierto es que la élite priísta, con todo y su desgaste a lo largo de este tiempo, ha dado muestras de que puede mantenerse unida en cierto tipo de circunstancias. La llegada al gobierno estatal de Arturo Montiel, político cuya trayectoria era muy pobre comparada con la de los anteriores mandatarios, sucedió en un momento en que los liderazgos sólo se mantenían a partir de apropiarse del partido y de una conocida habilidad para conciliar. 
A pesar de las similitudes de la unidad de mediados de siglo, lo cierto es que estamos presenciando una unidad distinta. Ahora la competencia política ha trastocado las viejas lealtades. En el marco de elecciones competidas, las expectativas individuales de los priístas mexiquenses no resultan necesariamente funcionales con la unidad de la clase política partidaria. La razón fundamental para ello es que en la medida en que no se dispone para repartir la totalidad de los cargos, se cuenta con una menor capacidad de inclusión de los perdedores. Ganar o perder pasó a ser así determinante para las expectativas a futuro. Lo llamativo de todo esto es que la unidad se mantiene sólo cuando se trata de una elección para gobernador y no para las presidencias municipales o diputaciones, donde el PRI ha sufrido un constante declive.

Esto dirige la mirada hacia las reglas políticas diseñadas por Fabela. Éstas fueron creadas en una época de crisis política y cuando estaba consolidado el dominio del partido oficial, pero ante el proceso de modernización, la pluralidad comenzó a crecer y a salirse de las manos de la élite local. Con el tiempo fue más difícil mantener la unidad en un medio más complejo y plural. Sin embargo, si bien la modernización política socavó la hegemonía electoral del partido oficial, las reglas no se han agotado.

Los triunfos en las elecciones para gobernador parecen indicar que ese es un ámbito respecto del cual la élite priísta local, a pesar de sus diferencias internas, guarda especial celo. En cambio, la dispersión de intereses y la pluralidad política intra y extra partidaria afloran en las elecciones intermedias, en las que la élite priísta local ha perdido la capacidad para observar las reglas que tanto tiempo le rindieron frutos. En suma, si bien la modernización minó las bases de dominio autoritario del prí́smo local, no agotó las reglas que ponen en marcha cuando se trata de conservar su razón de ser como clase política.

Dicho de otra manera, sólo cuando está en competencia por la gubernatura, la élite priísta local logra el control de la red y distribuye las aspiraciones según códigos de autoridad y representación grupal. En las elecciones intermedias, y en general en aquellas contiendas donde no existe un bien u objetivo único, los grupos tienden a dispersarse y se niegan a negociar porque pueden prescindir en parte o totalmente del resto de los grupos para mantener su dominio en una demarcación electoral. La clase política priísta termina dividiéndose cuando considera innecesarias la disciplina y las reactualizadas reglas de cohesión partidista. Resulta ventajoso para sus integrantes competir en lugar de observar las viejas lealtades. De todos modos, estas reglas han 
ido perdiendo su validez intrínseca y requirieron de incentivos adicionales para garantizar su eficacia.

\section{Los panistas: doctrina y pragmatismo}

Desde su fundación, el Partido Acción Nacional operó bajo la premisa de que "la lucha por el cambio político en México comienza con movimientos de defensa territorial desde el norte en contra del centro, esto es, contra el gobierno federal y el centralismo político y económico (Loaeza, 1999: 96). Ello explica el hecho de que en sus inicios haya buscado orientarse prioritariamente hacia un crecimiento regional para después buscar ganar la presidencia de la República. Se intentaba acceder al centro del sistema político mexicano (la presidencia) a través de estrategias regionales, presentándose como una opción política viable primero en el ámbito local.

Desde que Manuel Gómez Morín fundó el partido, se aprovecharon los lazos de amistad que éste tenía con personalidades de diferentes regiones del país, así formaron algunos liderazgos locales que favorecieron la presencia del partido en regiones en las que los cacicazgos afines al PRI lo permitían. En virtud de eso,

... en 1939 el partido se inició como una convocatoria de Manuel Gómez Morín y Efraín González Luna a sus redes de relaciones personales, a los notables locales de la época en ciudades como Chihuahua, Guadalajara, Mérida, Monterrey, Morelia, Oaxaca, Querétaro, San Luis Potosí, Tampico y, desde luego, el Distrito Federal, de suerte que desde su fundación el PAN contaba con una infraestructura de organización fuera de la capital de la República, aunque débil y limitada (Loaeza, 1999: 98).

Años más tarde, a mediados de la década de los cuarenta, el PAN “optó por la conquista del municipio como la vía de acceso al poder; por consiguiente, se propuso a sí mismo como el principal abanderado de la causa municipalista en México” (Loaeza, 1999: 216).

Lo anterior explica porqué Acción Nacional durante muchos años propuso autonomía en la hacienda de los partidos políticos, lo que suponía independencia del gobierno central, esto con el fin de neutralizar a los poderosos cacicazgos locales. A pesar de ello, Reveles (2002) distingue una paradoja en esta causa regionalista, ya que a pesar de buscar convertirse en una opción de poder local como medio de expansión política, persistía un fé- 
rreo control centralizado tanto en las dirigencias estatales como en la dirigencia nacional.

Aun cuando su constitución a nivel nacional data de 1939, fue durante la década de los sesenta que, apoyados por el Comité Ejecutivo Nacional, Víctor Guerrero y Astolfo Vicencio fundaron el Partido Acción Nacional (PAN) en el Estado de México.

Los panistas fundadores en la entidad se caracterizaron por su perfil doctrinario, con un fuerte apego a los principios y valores de su partido. De cierto modo fueron los ideólogos de Acción Nacional que difundieron los valores partidistas a los nuevos simpatizantes. Por otro lado, resultaba muy común la vinculación del partido con organizaciones católicas, las cuales representaban un medio de socialización ideológica e intercambio de ideas y proyectos. ${ }^{6}$ Sin embargo, es precisamente durante la época en que mayor vinculación existía entre ellos cuando los resultados electorales eran cada vez menos alentadores tanto en el Estado de México como en el resto del país.

El estancamiento electoral del PAN, durante ese periodo de radicalización católica se puede explicar en gran medida por la mezcla de política y religión en un país en el que el gobierno se había pronunciado por un laicismo exacerbado (Martínez Valle, 2000), a pesar de ello, es necesario reconocer que el componente católico en los inicios de Acción Nacional tuvo una función dual: por un lado "fue la espina dorsal que sostuvo a la titubeante organización partidista en un medio hostil, pero fue también un obstáculo para que el partido se desarrollara como una organización política autónoma” (Loaeza, 1999: 24).

Para los integrantes del PAN representar a la oposición era un reto y requería una gran vocación para seguir en el partido. Como muy pocas personas tenían la intención de competir por una candidatura de oposición cuya derrota estaba asegurada, resultaba relativamente sencillo ser favorecido con la nominación o tener un cargo dentro del partido, incluso algunos candidatos competían casi a la fuerza. Ganar un escaño (generalmente por vía plurinominal) era causa de gran orgullo y responsabilidad para con el partido (Niño Martínez, 2004).

La supervivencia ante un panorama tan adverso permitió la construcción de una gran unidad a lo largo de la geografía esta-

\footnotetext{
${ }^{6}$ Para nadie es un secreto la identificación que tiene el PAN con los postulados de la Iglesia católica, este vínculo data de los inicios del partido, tan es así que José González Torres, dirigente nacional del partido de 1959 a 1962 "quiso acercar todavía más al partido hacia una posición más abiertamente católica que se identificara políticamente con la democracia cristiana" (Martínez Valle, 2000: 52).
} 
tal, forjada a través de los conflictos con el régimen y la defensa del voto, por lo que desde entonces se distingue una colaboración entre panistas de diferentes regiones. También la unidad y estabilidad interna se definieron por la confianza en los procedimientos para la selección de candidatos, a quienes no se les exigía de manera exhaustiva debido a las pocas oportunidades de triunfo a la que se enfrentaban los candidatos.

El hecho de que no hayan existido rupturas graves en el partido se atribuyó a que los militantes se sumaban a un proyecto político institucional e ideológico y no en favor de un grupo o líder en específico, luego entonces, la suma de apoyos a un candidato era más de tipo coyuntural (Niño Martínez, 2004).

La unidad partidaria del panismo mexiquense, sostenida desde la rigidez doctrinaria y el pedigrí político, comenzó a verse seriamente amenazada casi al mismo tiempo en que se hizo más notable su presencia electoral. Hasta entonces dicho partido gozó de una estabilidad tal que fue controlado por una especie de dualidad de liderazgo entre Víctor Guerrero y Astolfo Vicencio. Estos dos personajes se mantuvieron cinco periodos al frente de la dirigencia, aproximadamente 15 años, lo cual se explica porque siendo un partido que tenía las derrotas electorales aseguradas, difícilmente los adeptos se sumaban a participar de manera activa en los trabajos del Comité Directivo Estatal.

Desde inicios de los noventa, la presencia electoral del PaN en el Estado de México se hizo más sólida y constante. El Valle de México se convirtió en una trinchera desde la cual los panistas aprendieron a combatir de forma eficaz la hegemonía del PRI. Municipios como Cuautitlán, Naucalpan, Atizapán y Tlalnepantla gradualmente pasaron a ser gobernados por panistas formando el "corredor azul".

Cuando las candidaturas panistas empezaron a convertirse en recursos apetecibles desde el punto de vista de las carreras políticas, los viejos mecanismos de selección de candidatos comenzaron a dar muestras de cierta ineficacia. Las posibilidades efectivas de triunfar en la gubernatura estatal -aunada a la forma en que se resolvió la candidatura presidencial de Vicente Fox, la cual se anticipó a los mecanismos partidarios y terminó por imponerse a las estructuras formales de decisión panista- obligaron al partido en la entidad a modificar el procedimiento, dando paso a un proceso de selección por medio de elecciones entre todos los militantes activos, en lugar de la tradicional asamblea.

Algunos investigadores tienden a afirmar que las elecciones recientes podrían dar alguna cohesión hacia el interior del parti- 
do, debido a que "el éxito electoral ha jugado un papel funcional para que la coalición dominante permanezca sin rupturas graves. Dadas las expectativas de triunfos, los panistas están poco dispuestos a la lucha interna y más orientados a la búsqueda de cargos de elección popular" (Reveles, 2002: 164), sin embargo, esta apreciación tan favorable no explica, entre otras cosas, ¿qué actitudes y compromisos mantienen aquellos grupos que no resultan beneficiados con las decisiones de las dirigencias nacional y estatal?, sobre todo considerando que entre los panistas no existe la tradición disciplinaria propia de los políticos del PRI.

Sin duda este nuevo pragmatismo predominante entre los políticos exitosos del PAN tiene como característica principal que los grupos internos tienden a estar poco cohesionados y a ser más coyunturales que los del régimen priísta. Esto representa un arma de dos filos ya que permite un reacomodo constante, pero por otro lado impide la formación de grupos políticos con vínculos fuertes, capaces de diseñar proyectos a largo plazo y sobre todo de favorecer la circulación de líderes tanto en el ámbito local como en el nacional, es por eso que "la posibilidad de conflicto, potencial y real, ha aumentado en el PAN desde que este partido dejó de ser oposición prácticamente permanente y pasó a ser una oposición real de poder" (Reynoso, 2005: 163).

\section{La elección de 2005: fracturas y unidades}

A pesar de que el abanderado panista Rubén Mendoza Ayala contó con el apoyo de Francisco Gárate Chapa, dirigente estatal del partido, fue incapaz de generar consenso alrededor de su candidatura. Peor aún, las acusaciones internas subieron de tono de forma sistemática, haciendo imposible una candidatura de unidad. El otro precandidato, José Luis Durán Reveles, manifestó su inconformidad ante la aparente parcialidad por parte de Francisco Gárate Chapa, líder estatal electo poco antes de la elección interna del partido, acusaciones éstas que fueron subiendo de tono conforme las internas del PAN se desarrollaban. ${ }^{7}$

El Comité Directivo Estatal del PAN padecía una gran fragmentación como consecuencia de las pugnas internas y los escándalos en torno de varias administraciones municipales de

${ }^{7}$ Los diarios locales dieron cuenta de esta situación, un ejemplo de los reclamos por parte de Durán hacia el dirigente estatal de su partido fue cuando afirmó que el Comité Directivo Estatal respaldaba a Mendoza Ayala, el cual, según él, había cometido violaciones al Código de Ética de Acción Nacional, exigiendo una sanción para su contrincante en las internas. El Sol de Toluca, 28 de octubre de 2004. 
militantes de Acción Nacional, mismas que se veían ensombrecidas por hechos de corrupción y salarios estratosféricos (Tultitlán, Ecatepec, Atizapán, etc.). Incluso poco antes de la elección de su candidato, se conformó el nuevo Comité Directivo Estatal y dejó de operar la delegación del Comité Ejecutivo Nacional encabezada por el senador Héctor Larios, misma que se encargó temporalmente de coordinar los trabajos políticos en la entidad como consecuencia de la disolución del Comité Directivo Estatal por parte de la dirigencia nacional del PAN. ${ }^{8}$

El proceso de selección del candidato panista a la gubernatura profundizó la desconfianza y los recelos entre dos grupos ya definidos con anterioridad, uno más apegado a los principios y valores históricos de Acción Nacional (representado por el grupo de José Luis Durán Reveles) y otro menos ideológico (personificado por Rubén Mendoza Ayala). Un ejemplo de lo anterior son las diferencias entre Juan Carlos Núñez Armas, colaborador de José Luis Durán Reveles durante su precampaña y ex presidente municipal de Toluca (2000-2003), y Armando Enríquez, alcalde de la capital estatal (2003-2006) y uno de los principales promotores de la candidatura de Mendoza Ayala.

Un elemento de singular importancia en este proceso fue que ambos precandidatos se encontraban fuertemente vinculados con los precandidatos panistas a la presidencia de la República. En este sentido, la unidad partidaria no constituía un bien común en la medida en que no sólo era importante ganar la candidatura al gobierno estatal sino que era, más importante aún, dirimir la candidatura federal. Así, las elecciones internas panistas del Estado de México fueron un escenario de prueba de la contienda federal y la derrota en el ámbito estatal no constituía el fin del proceso federal. No había pues, razones de peso para evitar que la contienda interna acabara en un acto de unidad partidaria frente a la elección estatal.

En el caso de Acción Nacional, el hecho de convertirse en la principal oposición partidista en sólo tres años representó una transformación muy importante, ya que en 1993, cuando el diri-

\footnotetext{
${ }^{8}$ Esta disolución se llevó a cabo con la mayor discreción, pero resulta muy importante distinguir que los entonces dirigentes estatales acataron sin protestar la decisión del Comité Ejecutivo Nacional (CEN). La delegación llevó a cabo los trabajos de organización para la designación de un nuevo dirigente, Juan Carlos Núñez Armas (identificado plenamente como colaborador de José Luis Durán Reveles), quien fue derrotado por una diferencia de sólo cuatro votos por Francisco Gárate Chapa, ex dirigente estatal (la desintegración del Comité Directivo Estatal se dio precisamente bajo su gestión) identificado con Rubén Mendoza Ayala.
} 
gente estatal era Noé Aguilar Tinajero, gobernaba sólo seis municipios y tenía tres diputados de representación proporcional (Niño Martínez, 2004). Ante este panorama, se diseñaron nuevas estrategias para contrarrestar el dominio abrumador que ejerció el PRI en las elecciones de 1996, sobresaliendo la creación de 10 centros regionales que les permitieron desconcentrar el trabajo político y fortalecer la presencia municipal y regional de Acción Nacional.

Sin embargo, el presentarse como una opción política con posibilidades reales de ganar trajo consigo otro tipo de problemas: uno de ellos definir en adelante quiénes serían los abanderados en las contiendas electorales, debido al incremento exponencial de aspirantes. Si bien antes esto no resultaba muy complicado para el Comité Estatal, la situación se había transformado radicalmente. Hubo entonces que modificar el proceso de selección de candidatos, lo cual significaba un reto formal para la estructura partidaria, que se podría sintetizar en la inclusión de los nuevos cuadros políticos jóvenes, con un proyecto que buscaba mayor impacto social que el de los panistas doctrinarios. De esta manera, ahora la posibilidad de elegir una alternativa ganadora incluía al menos dos opciones: PRI O PAN.

Finalmente, en el caso del PRI, las elecciones locales garantizaban el triunfo a quien fuera candidato, sin embargo, al consolidarse la competencia electoral y presentarse al menos otra alternativa de triunfo partidista diferente, las cosas fueron cambiando sistemáticamente. El partido enfrentó la necesidad, inédita hasta entonces, de que los aspirantes derrotados en las internas manifestaran su lealtad hacia el partido y sobre todo a la decisión del gobernador saliente, en el sentido de que una de las prácticas comunes de los gobernadores que terminaron su mandato ha sido la de nombrar a su sucesor, Arturo Montiel no fue la excepción y desde que se abrió el proceso para elegir al candidato priísta a la gubernatura dejó ver su preferencia por su paisano Enrique Peña Nieto.

A diferencia de Acción Nacional, para el caso del PRI, las expectativas de los aspirantes en la elección interna se solventaron gracias a que éstas podían atenuarse por la posición que garantizaba al gobernador saliente ser un competidor importante en la carrera hacia la presidencia del país.

Los demás precandidatos acataron la decisión del gobernador saliente respecto de la preferencia que éste tenía para que Enrique Peña Nieto fuera el candidato del PRI al gobierno estatal, todos, excepto Isidro Pastor, líder estatal del partido, quien al no 
disciplinarse automáticamente cerró las puertas de la negociación si acaso Arturo Montiel resultaba electo candidato presidencial. Este proceso no fue fácil, pues desde 1999, cuando por primera vez se llevaron a cabo elecciones internas en el PRI para la designación de su candidato, fue evidente la falta de madurez para disciplinar a los grupos perdedores. Sin embargo, el hecho de que dicho partido todavía contara con la presidencia, le facilitó unir a los grupos en torno a una candidatura. Posteriormente, y tras la pérdida de la presidencia, llegan Roberto Madrazo, otrora precandidato presidencial derrotado, y Elba Esther Gordillo a la dirigencia del partido, superando a Beatriz Paredes, cuyo apoyo de los políticos del Estado de México fue contundente.

Estas diferencias entre el PRI nacional y el del Estado de México se manifiestan nuevamente en el contexto de la carrera presidencial de 2006. Madrazo quería la candidatura de su partido para la presidencia de la República, pero una de sus mayores dificultades es que no disponía de la colaboración de los mexiquenses cuya fuerza electoral, después del Distrito Federal -perteneciente al PRD- es decisiva.

La confrontación entre Madrazo y Montiel terminó unificando a la élite priísta mexiquense. Las diferencias entre ambos eran tan profundas, y las cuentas pendientes tan abultadas, que sólo una posible candidatura de Montiel a la presidencia de la República podía garantizar a la élite local recursos a futuro.

\section{Conclusiones}

Hemos partido del principio según el cual en la democracia los gobiernos se crean a partir de la competencia entre las élites políticas partidarias, que éstas luchan por ganarse el apoyo del electorado y que en esa búsqueda las élites tratan de maximizar sus ventajas y optimizar sus recursos. Desde este punto de partida afirmamos que la unidad de las élites partidarias constituye un recurso fundamental para la competencia, y por ello, en particular pretendimos analizar en las páginas precedentes la importancia de la existencia de factores de cohesión de las élites partidarias en la contienda por la gubernatura del Estado de México de julio de 2005.

Tomamos dicha elección por lo imprevisto del resultado. Los resultados electorales previos y los posteriores así lo colocan. En una perspectiva de 10 años, podemos percibir, sin embargo, que sólo las dos últimas elecciones para gobernador en la entidad 
produjeron resultados inesperados en el mismo sentido, lo cual fue especialmente atractivo para nuestro análisis.

El que en la gubernatura mexiquense no se hubiese presentado la alternancia resultaba igualmente atípico por otras razones. Así como en otros ámbitos los resultados electorales en la entidad producen una integración de los poderes públicos que siguen patrones observables en otras entidades federativas de la República, las elecciones por la gubernatura se apartaron visiblemente de esos patrones.

Si el caso, entonces, se apartaba de la norma, la explicación de esta atipicidad debía buscar canales diferentes a los que la sustentaba. La búsqueda de perfiles sociodemográficos, culturales y políticos respecto del electorado resultaban, por ello, verdaderamente insuficientes. Si bien el Estado de México muestra transformaciones socioeconómicas que, de acuerdo con la visión dominante respecto de las causas de la transición, debieron favorecer la alternancia en el ejecutivo estatal, los análisis basados en dichas transformaciones sólo sirvieron para explicar el avance del PAN y del PRD en las otras elecciones (tanto locales como federales) celebradas en la entidad, pero no en las de la gubernatura.

Nuestra búsqueda se dirigió, entonces, a los partidos políticos. En este terreno sostuvimos que las particularidades de la competencia política en México y, en especial, las del sistema electoral, favorecieron la cartelización de los partidos políticos. Como consecuencia de ello, se desplegó un proceso de profesionalización de las élites partidarias que minaron la fortaleza de los recursos cohesivos de los partidos políticos, como la ideología, las lealtades y la disciplina.

Este hecho resulta ampliamente significativo para nuestro estudio debido a que la falta de unidad de las élites partidarias mexiquenses había sido un rasgo distintivo de las campañas electorales para los comicios del 2005. No obstante, percibimos que, si bien la cartelización de los partidos resultaba un hecho generalizado, los recursos para procurar la unidad de las élites partidistas se mostraban diferentes en cada caso.

Para poder evaluar la disponibilidad de los recursos de unidad con que contaban las élites partidistas y sus particularidades, recurrimos a la reconstrucción de la evolución de la institucionalización de los principales partidos en la entidad.

Como resultado de ese ejercicio, detectamos que el recurso de unidad más importante para el PRI en el Estado de México era el acuerdo tácito sobre unas reglas del juego que suponían la 
inclusión de los diferentes grupos que componen su élite. En la medida en que las reglas permitían el reconocimiento de espacios para ganadores y perdedores, la búsqueda de estrategias competitivas radicales entre los integrantes de la élite carecía de sentido, fortaleciendo la unidad.

Mientras las características de la competencia política permitieron al PRI conquistar prácticamente la totalidad de los espacios político-institucionales, la disposición de incentivos suficientes desalentó la competencia interna excluyente y se destinaron la mayor parte de los esfuerzos a desincentivar la competencia externa y la distribución de los espacios de poder. En el momento en el que dicho partido no pudo evitar la pluralidad política partidista, la reducción de los espacios y el carácter selectivo de los incentivos, se disparó la competencia interna.

En el caso del pan mexiquense, la fortaleza de los recursos de cohesión institucional no descansaba, como en el caso del PRI, en el control poco menos que absoluto de los puestos públicos y/o de elección popular, sino, por el contrario, en la imposibilidad poco menos que absoluta de acceder a los mismos. La dificultad para ganar las elecciones desalentaba la competencia interna por las candidaturas, que adquirían un valor exclusivamente simbólico y al que sólo por razones ideológicas era razonable aspirar.

La pluralización de la competencia política tuvo un efecto igualmente corrosivo para la unidad partidaria. En la medida en que triunfar en una elección era posible, la competencia por las candidaturas se veía incentivada por las recompensas asociadas al puesto. Si había recursos para distribuir de manera selectiva, la aspiración a obtenerlos desató la competencia interna. Así, de un partido cuasi monolítico, el PAN se convirtió en uno surcado por grupos y debilitado en su unidad. Si bien su alto grado de institucionalización le permitió canalizar la competencia interna por el sendero del respeto a las reglas, éstas debieron ajustarse progresivamente no siempre generando consensos, las conductas desleales afloraron y la búsqueda de los intersticios reglamentarios se volvió práctica generalizada.

Los dos partidos llegaron, pues, a los comicios de julio del 2005 con similares potencialidades centrífugas en lo que hace a la competencia entre los grupos que conforman sus élites partidarias. Los antecedentes electorales, a su vez, dispararon la existencia de condiciones para el éxito de los dos partidos, lo cual alentaba conductas no cooperativas. Sin embargo, el PRI fue el único que logró de manera más o menos exitosa conservar la unidad. 
El breve espacio de tiempo que separa la elección presidencial de la de gobernador en la entidad y lo anticipado de las campañas y precampañas federales tuvieron su influencia en la elección local. De modo que por momentos fue difícil distinguir las campañas en uno y otro ámbito. En los tres casos, los procesos de selección de candidatos a la gubernatura estuvieron fuertemente influenciados por los alineamientos en torno de las precandidaturas presidenciales de sus respectivos partidos.

El priísmo, en el ámbito federal, se encontraba fuertemente dividido desde la precampaña electoral del 2000 y la posterior derrota en la elección presidencial. Desde ese momento, y en especial desde que el priísmo mexiquense apoyó a Beatriz Paredes para la presidencia del Comité Ejecutivo Nacional del partido, las relaciones con el madracismo se encontraban muy deterioradas. De esa manera, y en la medida en que el gobernador saliente competía contra Madrazo por la candidatura presidencial del PRI, la élite partidaria local sabía que la única manera de obtener beneficios políticos de corto plazo pasaba por apoyar las intenciones de Arturo Montiel con todas las capacidades institucionales del priísmo local (el del estado más importante gobernado por este partido). Y ese fue su mayor recurso de unidad, complementado por una larga tradición política que, aunque debilitada profundamente, seguía siendo valorada por los políticos mexiquenses priístas y por el temor a las sanciones en el caso de que no lo apoyaran y Arturo Montiel llegara a la candidatura presidencial del PRI.

En el caso del panismo no existió tal factor de cohesión. Las precandidaturas a la gubernatura reprodujeron las pugnas federales y puede decirse que fueron su escenario de pruebas. Al mismo tiempo, el panismo mexiquense no encontraba incentivos para concentrar todos sus esfuerzos en una única opción. Por el contrario, la élite local panista tenía fuertes estímulos para disgregarse entre las diferentes opciones federales porque en todas encontraba oportunidades de rendimientos futuros. De este modo, el panismo trasladó, hasta el día mismo de la elección mexiquense, las señales y alineamientos de la contienda federal.

Desde nuestro punto de vista, un aspecto que la democracia competitiva provoca en los partidos políticos y sus élites es que si bien incentiva a competir en la búsqueda del voto, paradójicamente esto mismo los enfrenta con sus debilidades estructurales.

En el caso estudiado, el paso de un sistema no competitivo a uno competitivo puso en contradicción la racionalidad individual de los políticos mexiquenses con la racionalidad colectiva 
de sus respectivas élites. Los comportamientos de los políticos liberados de la necesidad de las viejas lealtades pluralizaron al sistema político al tiempo que debilitaron la unidad de los partidos. No obstante las ventajas que en lo individual obtuvieron algunos políticos al desconocer las viejas lealtades y compromisos, lo cierto es que en el mediano plazo la falta de cohesión de las élites políticas debilitó la posición de los partidos en el mercado electoral.

Inservibles los viejos mecanismos de unidad, sólo la apelación a recursos extraordinarios lograron restaurarla temporalmente, lo cual redundó en un reposicionamiento en el mercado electoral. Así, ante las potencialidades centrífugas de las élites políticas locales, la del PRI consiguió, a partir de factores externos y coyunturales, una candidatura de unidad en la que concentró todos sus esfuerzos, los demás partidos no tuvieron recursos semejantes, lo cual resultó coyunturalmente decisivo.

No obstante, si los partidos no encuentran razones y mecanismos más sólidos para garantizar la unidad como un bien colectivo, estarán expuestos a la necesidad de encontrar recursos extraordinarios para imponerse en los sucesivos comicios o a perder las elecciones, lo cual puede redundar en una espiral de debilitamiento organizacional que haga cada vez más difícil su permanencia institucional.

\section{Bibliografía}

Becerra, Ricardo, Salazar, Pedro y José Woldenberg (2000), La mecánica del cambio político en México. Elecciones, partidos y reformas, Cal y Arena, México.

Cansino, César (2000): La transición mexicana 1977-2000, CEPcom, México.

CONAPO-PROGRESA (1995): Índices de marginación, México: CONAPO.

Grupo Financiero Banamex-Accival (2005): México Electoral, Estadísticas Federales y Locales 1970-2004, Estudios Económicos y Sociopolíticos Grupo Financiero BanamexAccival, México.

Hernández-Rodríguez, Rogelio (1998): Amistades, compromisos y lealtades: líderes y grupos políticos en el Estado de México, 1942-1993, El Colegio de México, México. 
Hernández-Rodríguez, Rogelio (1999): "Los políticos del Estado de México: entre la dispersión y la competencia" en Bazant, Milada: 175 años de la historia del Estado de México y perspectivas para el tercer milenio, El Colegio Mexiquense, Zinacantepec, pp. 455-480.

Landero-Gutiérrez, Alejandro (2004): La lucha cívica por la democracia. Breve historia del Partido Acción Nacional. Fundación Rafael Preciado Hernández A.C., México.

Loaeza, Soledad (1999): El Partido Acción Nacional: la larga marcha, 1939-1994. Oposición leal y partido de protesta, FCE, México.

Martínez-Valle, Adolfo (2000): El Partido Acción Nacional: una historia política, Porrúa, México.

Molinar-Horcasitas, Juan (1991): El tiempo de la legitimidad. Elecciones, autoritarismo y democracia en México, Cal y Arena, México.

Niño-Martínez, José Javier (2004): La política en transición. La competencia electoral y los políticos en la capital del Estado de México, Tesis de Maestría, Instituto de Investigaciones Sociales Dr. José María Luís Mora, México.

Olson, Mancur (1992): La lógica de la acción colectiva. Bienes públicos y teoría de grupos, Limusa, México.

Pacheco, Guadalupe (2000): Calidoscopio electoral. Elecciones en México, 1979-1997, FCE, México.

Paris-Pombo, María Dolores (2000) "La agonía del nacionalismo revolucionario y el despertar del regionalismo entre las elites políticas mexicanas” en: Labastida Martín del Campo, Julio, Camou, Antonio y Noemí Luján Ponce (coords.) Transición democrática y gobernabilidad: méxico y américa latina, Plaza y Valdés-unAm-Flacso, México, pp. 107-130.

Peschard, Jacqueline (1988): "Las elecciones en el Distrito Federal (1946-1970)", Revista Mexicana de Sociología, Año L / Nro. 3, Julio-Septiembre, unAm, México, pp. 229-246. 
Peschard, Jacqueline (2005): "Los retos de los partidos políticos en la postransición” en Reveles Vázquez, Francisco: Los partidos políticos en México ¿Crisis, adaptación o transformación? Gernika, México, pp. 41-59.

Przeworski, Adam (1995): Democracia y mercado: reformas políticas y económicas en la Europa del Este y América Latina, Cambridge University Press, Cambridge.

Reveles-Vázquez, Francisco (Coord.) (2002): Partido Acción Nacional: los signos de la institucionalización, UNAM-Guernika, México.

Reveles-Vázquez, Francisco (2005): Teorías y realidades de los partidos políticos: Una lectura desde México, Ponencia presentada en el Seminario Permanente en Partidos Políticos y Sistemas Electorales, Toluca: UAEM.

Reynoso, Víctor Manuel (2005): "La institucionalidad panista: situación actual y perpectivas”, en Reveles Vázquez, Francisco: Los partidos políticos en México ¿Crisis, adaptación o transformación? Gernika, México, pp. 141-163.

Salazar-Medina, Julián (coord.) (1993): Estructura y dinámica del poder en el Estado de México, uAEM, Toluca.

Sánchez, Marco Aurelio (1999): PRD: La élite en crisis. Problemas organizativos, indeterminación ideológica y deficiencias programáticas, Plaza y Valdés, México.

Schumpeter, Joseph (1983): Capitalismo, socialismo y democracia, Orbis, Barcelona.

Vargas-González, Pablo (2002): "Las elites locales y su cultura políticas en la consolidación democrática", Nueva Antropología, Nueva Antropología A.C., México. pp. 127-144.

\section{Páginas de internet}

http://www.ieem.org.mx

http://www.cidac.org 
Fuentes hemerográficas

El Heraldo de Toluca, El Sol de Toluca y La Jornada

Recibido: 13 de septiembre de 2006. Aceptado: 29 de enero de 2007.

Javier Ariel Arzuaga Magnoni. Es doctor en ciencias sociales. Actualmente se encuentra adscrito a la Facultad de Ciencias Políticas y Administración Pública, UAEM. Sus líneas de investigación se centran en: elecciones y élites políticas en el Estado de México. Entre sus publicaciones más recientes se encuentran: Reflexiones de política democrática (2006), en coautoría con Ramiro Medrano González, Ivett Tinoco García e Igor Vivero Ávila (comps.), vol. 1, Instituto Electoral del Estado de México, Universidad Autónoma del Estado de México; "Democracia y consenso. Una apuesta al gobierno de lo local” (2001), Espacios Públicos, Universidad Autónoma del Estado de México (Facultad de Ciencias Políticas y Administración Pública), Año 4(7), Toluca, pp. 67-74; Razones del cambio en las elecciones presidenciales en el Estado de México" (2002) en coautoría con Javier y Carlos Alberto Sara Gutiérrez, Economía, Sociedad y Territorio, El Colegio Mexiquense, A.C., III(II), Zinacantepec, pp. 441-470.

Orlando Espinosa Santiago. Es maestro en sociología política; actualmente se encuentra adscrito a la Facultad de Ciencias Políticas y Administración Pública, UAEM. Su línea de investigación se centra en caudillismo y élites políticas.

José Javier Niño Martínez. Es maestro en sociología política. Actualmente se encuentra adscrito a la Facultad de Ciencias Políticas y Administración Pública, UAEM. Su línea de investigación se centra en élites políticas partidarias en el Estado de México. 